Journal of Engineering and Applied Sciences 14 (Special Issue 6): 9477-9481, 2019

ISSN: 1816-949X

(C) Medwell Journals, 2019

\title{
Analysis of Merra-2 Climate Data for Hillah City Iraq
}

\author{
Iqbal H. Abdulkareem \\ Environmental Research and Studies Center, University of Babylon, Babylon, Iraq
}

\begin{abstract}
Climate change became an important filed of research. It is believed that climate change may be one of the greatest threats facing the Earth's ecosystem. Recent years show increasing temperatures in various regions and/or increasing extremities in weather patterns. This research explore the trends in various weather elements over the Hillah city in central Iraq using Merra-2 data for 37 years (1980-2016). The results indicated that the most affected elements by climate change were the temperature and precipitation. Temperature trend is increasing while precipitation is slightly decreasing over the 37 years period. Other weather elements such as atmospheric pressure, relative humidity and wind showed no distinct trends and their patterns are those of arid and semi-arid regions. Low-pressure patterns and dry conditions during Summer and high-pressure patterns and wet Winter. The wind during Summer is higher than its values during Winter. The wind direction is mostly Northwesterly.
\end{abstract}

Key words: Hillah, Winter, atmospheric pressure, semi-arid regions, wind, temperature

\section{INTRODUCTION}

Climate change of the Earth is caused by climate variability, a non-man made processes that affect the global atmosphere and human activities. Human effects on global atmosphere were very different before and after the industrial revolution. Before the revolution, most climate changes were attributed to climate variability while after the revolution human activities are considered the major contributor to global warming. Global warming is a result of increasing the concentration of greenhouse gas such as carbon dioxide and methane. Research works indicated that global air temperature is continually increasing, since, the beginning of the last century and presents a serious threat to nature and people (Dessler, 2015). There is new and stronger evidence that most of the warming observed over the last 50 years is attributable to human activity and both the temperature and the sea-level are projected to continue rise throughout the twenty-first century.

There has been an extensive research works on climate change worldwide and on the possible consequences of human activities on the Earth climate. In Iraq, many researchers worked the influence of global climate change on the local climate. Recently many research works have been conducted on the influence of climate change on Iraq and surrounding regions, e.g., Zakaria et al. (2013) reported on historical and future climatic change scenarios for temperature and rainfall for Iraq, Bilal et al. (2013) investigated trends of temperature in the period 1941-2000 for Baghdad, Iraq. They found that the mean temperature was significantly increased during the months of April and July and decreased during November. Abdou (2014) studied temperature trend on Makkah, Saudi Arabia and concluded that the annual mean of daily mean, maximum and minimum temperature increased by $0.0398,0.0552,0.0398^{\circ} \mathrm{C}$ per year, respectively. Azooz and Talal (2015) provided an evidence of climate change in Iraq. Nahlah et al. (2016) assessed climate change impact on water resources of Lesser Zab, Kurdistan, Iraq using SWAT Model. Tarawneh and Chowdhury (2018) studied trends of climate change in Saudi Arabia to determine the implications on water resources. Karimi et al. (2018) studied the climate change and agriculture: impacts and adaptive responses in Iran.

\section{MATERIALS AND METHODS}

Hillah is the capital of the Babylon Province in central Iraq, just South of the country's capital Baghdad. The city is located on the Hilla branch of the Euphrates river adjacent to the ancient city of Babylon and close to the ancient cities of Borsippa and Kish. Its geographical coordinates are $32.48^{\circ}$ Nand $44.43^{\circ} \mathrm{E}$. To asset recent climatic variation of Hillah, monthly means of various weather elements for the period 1980-2016 were used. The data were obtained from the Modern-era retrospective analysis for research and applications, Version 2 (MERRA-2). MERRA-2 is the latest atmospheric re analysis of the modern satellite era produced by NASA's Global Modeling and Assimilation Office (GMAO) (Gelaro et al., 2017). The data includes monthly means of air daily air temperature, relative humidity, atmospheric 
pressure, wind speed, wind direction and monthly total of rainfall. Surfer commercial software was used to grid and generate month-year maps for these weather elements. Time series was used to determine the trends for the elements.

\section{RESULTS AND DISCUSSION}

Figure 1 shows the variations of monthly means for pressure, temperature, relative humidity and precipitation for the period from 1980-2016. These results indicate that Hillah is characterized by high pressure patterns during Winter and low pressure patterns during Summer. It is noticeable that pressure could fluctuate around the mean value during mid Summer (July) and Winter (December and January) temperature ranges from $10-15^{\circ} \mathrm{C}$ during Winter months (Dec to Feb) and $35-40^{\circ} \mathrm{C}$ during Summer months (Jun to Aug). It is clear that temperature cloud be lower than $10^{\circ} \mathrm{C}$ during Winter and may slightly reaches more than $40^{\circ} \mathrm{C}$ during Summer. The relative humidity results illustrate that Hillah is characterized by dry air during Summer and moderately wet air during Winter. The rainfall pattern shows that rainfalls during the rainy season (Oct to May) in the city and varies form 1 year to
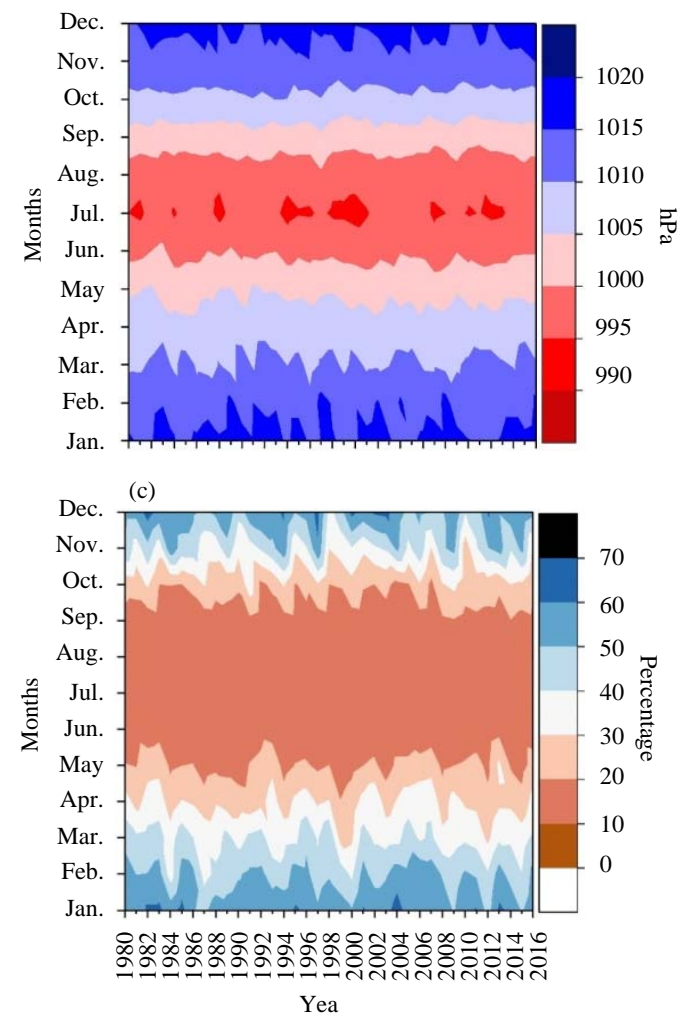

another and there is no distinct trend for rainfall. Figure 2 shows the histograms of the weather parameters. It is seen that highest pressure is $1015 \mathrm{hPa}$ during Dec and Jan and the lowest pressure is $995 \mathrm{hPa}$ during Jul. The hottest months are Jul and Aug this is due to the lag time between maximum solar radiation reaching Earth surface (22 Jun) and maximum temperature. The lag time is about 25 days which means that maximum temperature occurs during mid Jul. Relative humidity data shows that during 6 months, from May to Oct, relative humidity barely reaches 25\%. During Winter, relative humidity can reach the $50 \%$. This is because hot air can hold more water vapor than cooler air. The rainfall data suggest that the rainy season in the city extends from Oct to May and maximum rain falls during the month of Jan. The results of the wind indicate that higher winds (more than $4 \mathrm{msec}^{-1}$ ) occurs during Summer and the prevailing direction is between and $300^{\circ}$. This Northwesterly wind pattern is a result of which is a result of the Shamal wind, a wind blowing over Iraq and the Arabian Gulf states (including Saudi Arabia and Kuwait), often strong during the day but decreasing at night. This weather effect occurs anywhere from once to several times a year, mostly in Summer but sometimes in Winter.
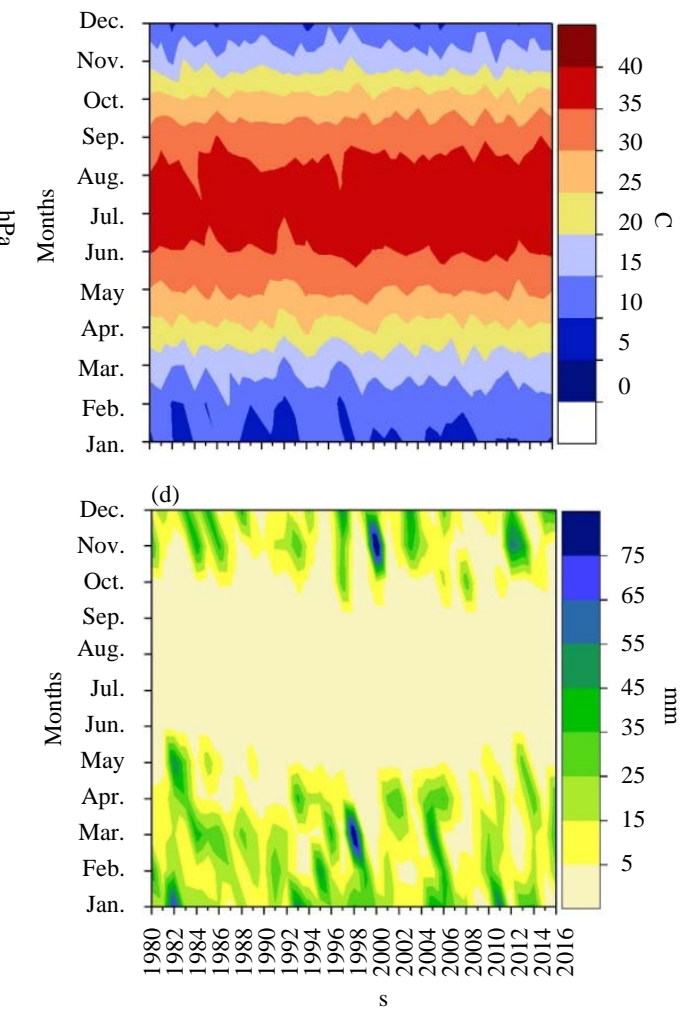

Fig. 1: Monthly means of atmospheric pressure, temperature, relative humidity and rainfall during 1980-2016 in Hillah city: (a) Pressure, (b) Temperature, (c) Relative humidity and (d) Rainfall 

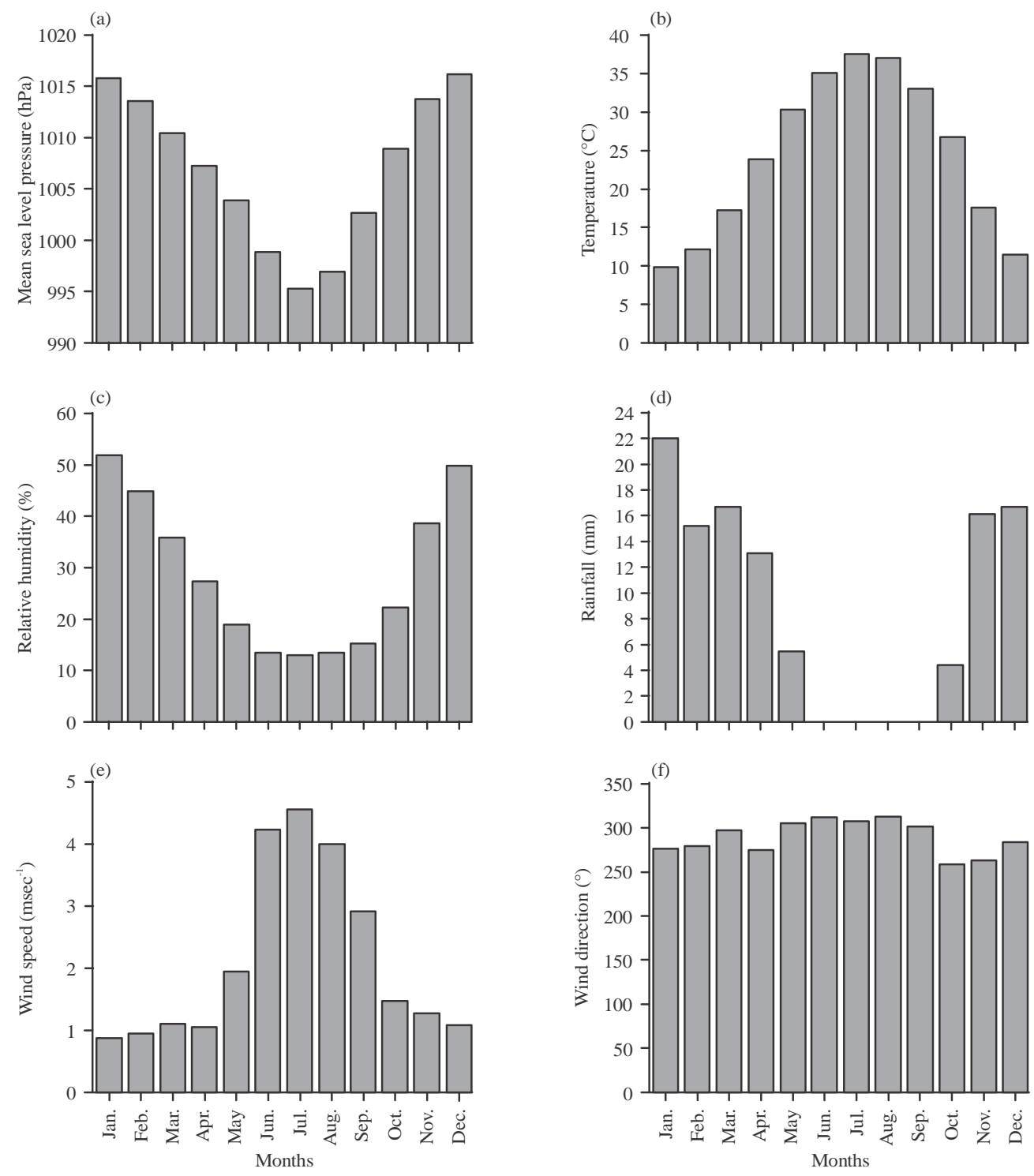

Fig. 2: Histograms of monthly means of atmospheric pressure, temperature, relative humidity, rainfall, wind speed and wind direction during 1980-2016 in Hillah city: (a) Pressure (b) Temperature (c) Relative humidity (d) Rainfall (e) Wind speed and (f) Wind direction

To asset the effects of global warming on the city of Hillah, anomalies were calculate for the weather elements for the period under study. Figure 3 shows the time series for these anomalies. The fluctuation of pressure is between -3 to $+3 \mathrm{hPa}$ and no trend is observed. The temperature fluctuates between -4 to +3 and noticeable increasing trend is observed. Relative humidity oscillates between -15 to $+15 \%$ and no distinct trend exists. The rainfall anomalies are quite complicated but in general values of positive anomalies are higher than negative ones and slight decrease in rainfall for the 37 years period is observed. The results illustrates that wind speed and direction have a positive trend. It is clear that positive anomalies of wind direction may $+50^{\circ}$. While negative anomalies may reach $-250^{\circ}$. In many occasions. These rather abnormal values may be attributed to Shurgee winds, a South Easterly winds that occasionally blow over the region. Figure 4 shows the time series for annual rainfall. The mean annual rainfall for 37 years is about $110 \mathrm{~mm}$ and the annual rainfall varies from 1 year to another but it can be seen that two distinct dry periods existed between 1997, 1992, 2007-2010. Figure 5 gives the wind rose which indicates that the majority of wind speeds lie between 1 and $4 \mathrm{msec}^{-1}$ and the prevailing wind is Nortwesterly. 

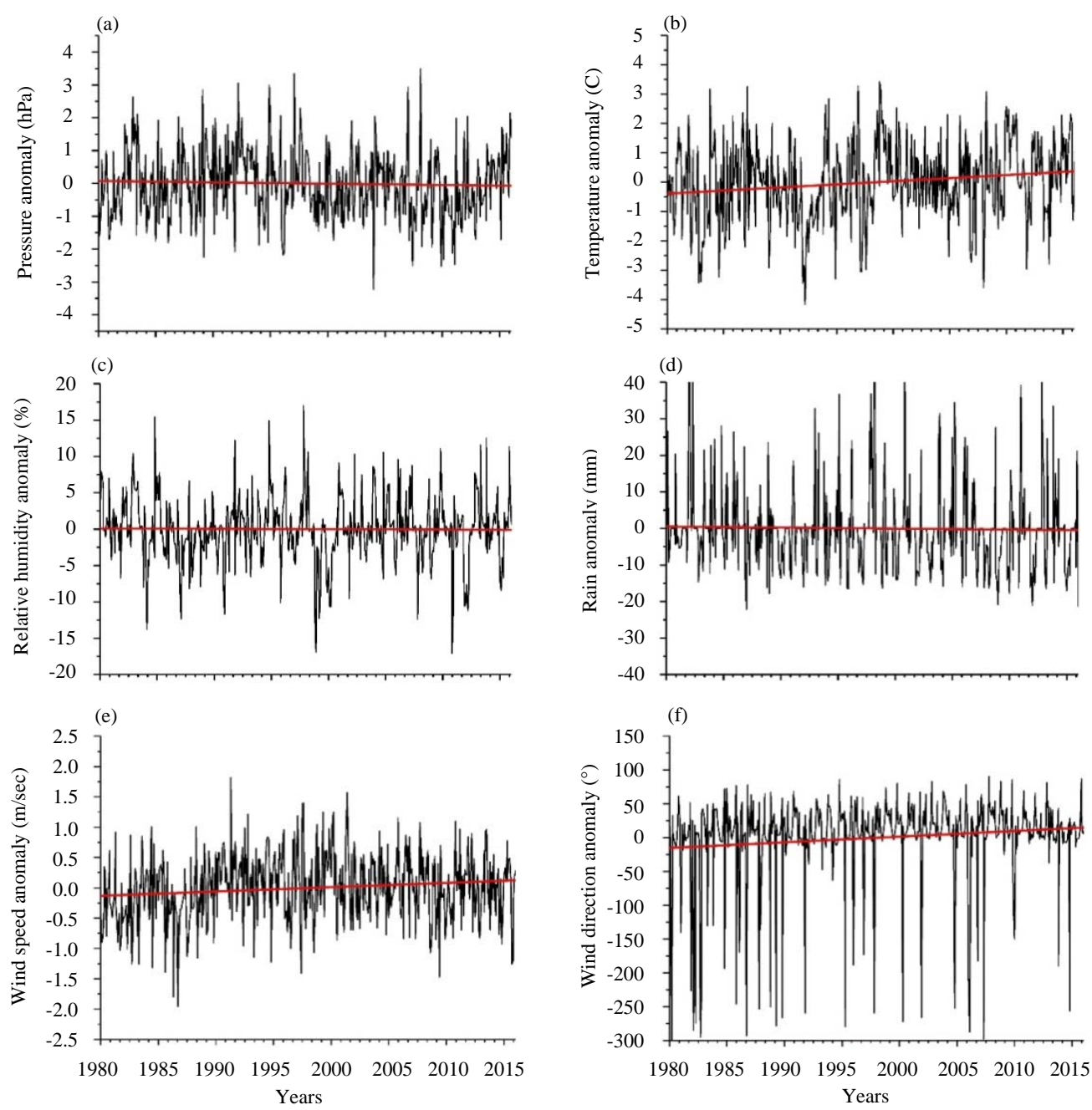

Fig. 3: Linear regressions of monthly means of atmospheric pressure, temperature, relative humidity, rainfall, wind speed and wind direction during 1980-2016 in Hillah city (a) Pressure (b) Temperature (c) Relative humidity (d) Rainfall (e) Wind speed and (f) Wind direction

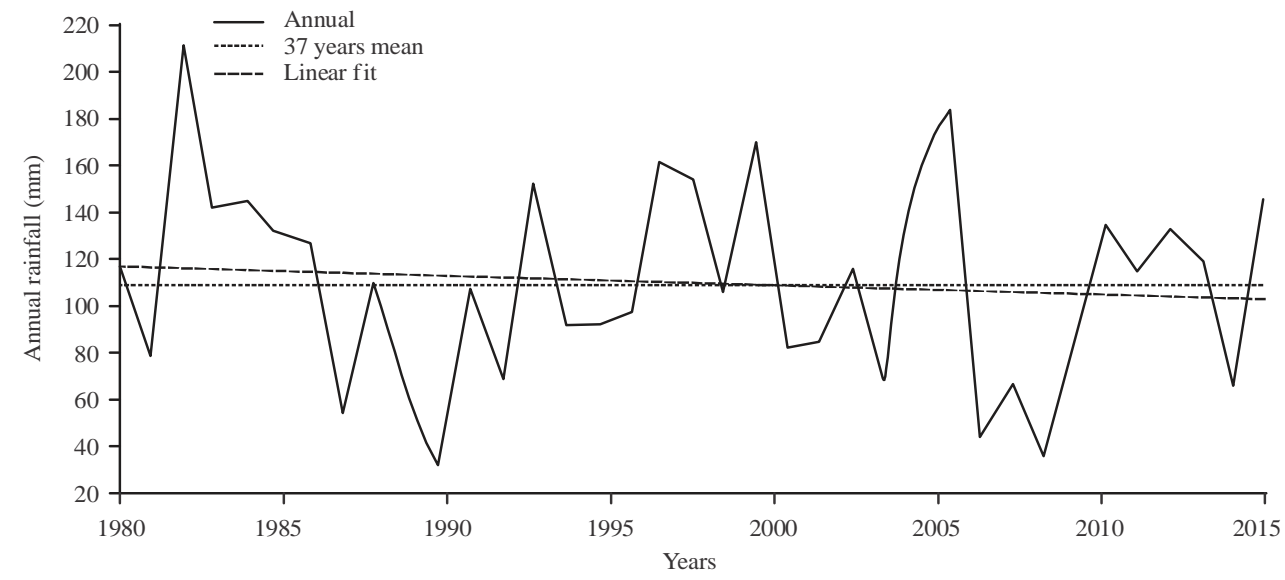

Fig. 4: Linear regression of annual rainfall for the period from 1980-2016 in Hillah city 


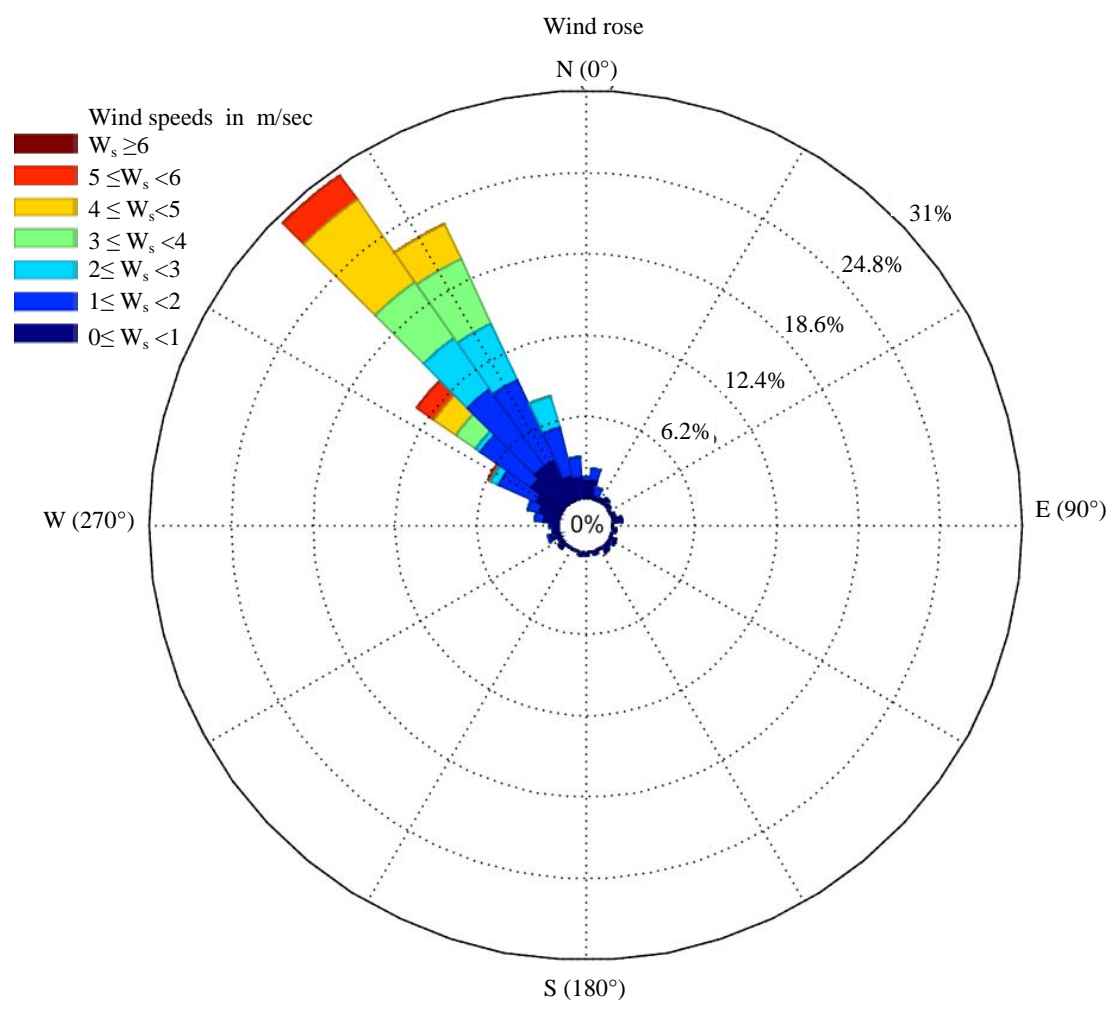

Fig. 5: Wind rose for the period from 1980-2016 in Hillah city

\section{CONCLUSION}

In this research MERRA-2 monthly means of various weather elements during the period 1980-2016 for Hillah city in central Iraq were analyzed. Results indicates that the city is influenced by the regional weather patterns such as high pressure during Winter and low pressure during Summer, cool Winter and very hot Summer. The city receives a mean annual rainfall of about $100 \mathrm{~mm}$. The wind is mostly North Westerly reach more than $6 \mathrm{msec}^{-1}$ during Summer. Regression analysis for 37 years of monthly means showed there is no distinct trends in pressure, relative humidity and wind while temperature showed increasing trend and precipitation slightly decreasing.

\section{REFERENCES}

Abdou, A.E.A., 2014. Temperature trend on Makkah, Saudi Arabia. Atmos. Clim. Sci., 4: 457-481.

Azooz, A.A. and S.K. Talal, 2015. Evidence of climate change in Iraq. J. Environ. Prot. Sustainable Dev., 1: 66-73.
Bilal, D.A., K.J. Al-Jumaily and E.A. Habbib, 2013. Air temperature trends in Baghdad, Iraq for the period 1941-2000. Intl. J. Sci. Res. Publ., 3: 1-5.

Dessler, A., 2015. Introduction to Modern Climate Change. 2nd Edn., Cambridge University Press, Cambridge, UK., ISBN:978-1-107-09682-0, Pages: 253.

Gelaro, R., W. McCarty, M.J. Suarez, R. Todling and A. Molod, 2017. The modern-era retrospective analysis for research and version 2 (MERRA-2). J. Clim., 1: 5419-5454.

Karimi, V., E. Karami and M. Keshavarz, 2018. Climate change and agriculture: Impacts and adaptive responses in Iran. J. Integr. Agric., 17: 1-15.

Nahlah, A., S.A. Wasimia and N. Al-Ansari, 2016. Assessment of climate change impact on water resources of lesser Zab, Kurdistan, Iraq Using SWAT model. Eng., 8: 697-715.

Tarawneh, Q. and S. Chowdhury, 2018. Trends of climate change in Saudi Arabia: Implications on water resources. Clim., 6: 1-8.

Zakaria, S., N. Al-Ansari and S. Knutsson, 2013. Historical and future climatic change scenarios for temperature and rainfall for Iraq. J. Civil Eng. Archit., 7: 1574-1594. 